\title{
Anticancer effects on TACC3 by treatment of paclitaxel in HPV-18 positive cervical carcinoma cells
}

\author{
EUN-KYOUNG YIM ${ }^{1,2^{*}}$, SEO-YUN TONG ${ }^{1,3^{*}}$, EUN-MI HO ${ }^{1}$, \\ JEONG-HOON BAE ${ }^{1}$, SOO-JONG $\mathrm{UM}^{4}$ and JONG-SUP PARK ${ }^{1}$ \\ ${ }^{1}$ Department of Obstetrics and Gynecology, Graduate School, The Catholic University of Korea, Seoul, \\ Korea; ${ }^{2}$ Department of Systems Biology, UT MD Anderson Cancer Center, Houston, TX, USA; \\ ${ }^{3}$ Department of Obstetrics and Gynecology, College of Medicine, Kyung-Hee University, East-West \\ Neo Medical Center, Seoul; ${ }^{4}$ Department of Biotechnology, Sejong University, Seoul, Korea
}

Received June 17, 2008; Accepted November 3, 2008

DOI: 10.3892/or_00000256

\begin{abstract}
Previously, we used proteome analysis to identify transforming acidic coiled coil (TACC) 3 as a protein that is down-regulated upon paclitaxel treatment in cervical cancer cells. TACC 3 mRNA and protein levels decreased after paclitaxel treatment in a time- and dose-dependent manner, and the transactivation of TACC3 promoter was dramatically diminished by paclitaxel. Importantly, paclitaxel treatment and knockdown of TACC3 by siRNA led to a synergistic enhancement of significant G2/M phase arrest and apoptosis in HeLa cells. In contrast to TACC3-deficient cells, paclitaxel treatment of mTACC3-overexpressing cells failed to induce G2/M phase arrest, cell growth inhibition, and apoptotic cell death. We studied the associated gene in mTACC overexpressed cells using microarray. From these results, numerous genes have been identified as being associated with tumor progression (Ppia, TMSB10, Annexin A2, rab31, prostaglandin E2-EP2, UHRF1), chemoresistance (Akt, Plk-1, MAP kinase) and metastasis (MMP9, PECAM-1) in mTACC3 overexpressed HeLa cells. Thus, TACC3 is thought to be the critical molecule in mediating the anticancer mechanisms of paclitaxel in p53 inactivated cells by inducing $\mathrm{G} 2 / \mathrm{M}$ arrest and apoptosis. And our data suggested that the overexpression of TACC 3 may be associated with the mechanisms of chemoresistance, tumor progression, cell proliferation and metastasis.
\end{abstract}

Correspondence to: Dr Jong-Sup Park, Department of Obstetrics and Gynecology, Graduate School of Catholic University, 505 Banpodong, Seocho-gu, Seoul 137-040, Korea

E-mail: jspark@ catholic.ac.kr

*Contributed equally

Key words: paclitaxel, TACC3, cervical cancer cells, chemoresistance, cDNA microarray

\section{Introduction}

Microtubules are highly dynamic cytoskeletal fibers that play an important role in the processes of mitosis and cell division, and are a target for anticancer drugs (1). The currently most successful microtubule-targeted chemotherapeutic agent is paclitaxel (1), which has been used to treat ovarian, breast, gastric, colorectal, lung and recurrent cervical cancer (2). Despite the relevant contribution of paclitaxel in ameliorating the quality of life and overall survival of cancer patients, drug resistance to paclitaxel represents an extremely important clinical problem. Many patients, even those who initially respond to therapy, fail to respond further during disease relapse, and a small number of patients do not even respond during the first cycle of therapy (3). Taxane, paclitaxel and docetaxel resistance is associated with multiple cellular events such as tubulin mutation (4), P-glycoprotein (Pg) overexpression (5), and increased microtubule dynamics associated with altered microtubule-associated protein (MAP) expression (6). In our previous study, we examined the anticancer mechanism of paclitaxel and analyzed the expression profiles of paclitaxeltreated HeLa cervical cancer cells by proteome analysis (2). Among the identified candidate target molecules, we focused on the characterization of the transforming acidic coiled-coil containing protein (TACC) 3. Lesperance et al (7) also reported using DNA microarray screening that TACC3 was one of the chemoresistant associated genes. The TACC family was originally identified as a group of three related proteins containing a highly homologous, C-terminal acidic coiledcoil domain; the respective genes localize at breast cancer amplicons and in a region disrupted in multiple myeloma $(8,9)$. The TACC 3 gene was the last of the family members to be identified in a yeast two-hybrid screen for ARNTinteracting proteins (9), and as an erythropoietin-induced gene in erythroid progenitor cells (10). TACC3 deficiency causes embryonic lethality during mid-to late gestation, which involves several lineages of cells and is associated with a high rate of apoptosis and elevated expression of the p53 target gene, p21Waf1/Cip1 (11). Thus, TACC3 is a critical component of the centrosome/mitotic spindle 
apparatus, and its absence triggers p53-mediated apoptosis. Schneider et al (12) also reported that TACC3 depletion strongly sensitized NIH3T3 cells to paclitaxel treatment by p53-dependent induction of p21WAF and cell cycle arrest. However, it has been reported that p53 status does not affect chemosensitivity of human ovarian cancer cell lines to paclitaxel (13). In cervical cancer cells, human papillomavirus (HPV) E6 disrupt the wild-type p53 function. In this study, we functionally characterized TACC 3 as a potential target of paclitaxel cytotoxicity by knockdown or overexpression of TACC3 in HPV-18 positive HeLa cells.

\section{Materials and methods}

Cell culture and cell growth measurement. HeLa cervical cancer cells were maintained in Dulbecco's modified Eagle's medium (DMEM) supplemented with $10 \%$ fetal bovine serum (Gibco BRL, Gaithersburg, $\mathrm{MD}$ ) at $37^{\circ} \mathrm{C}$ in $5 \% \mathrm{CO}_{2}$. Subconfluent proliferating cells plated in 96-well plates were treated with different doses of paclitaxel, and assayed for MTT [3-(4,5-dimethylthiazol-2-yl)-2,5-diphenyltetrazolium bromide] (Sigma, St. Louis, MO) reduction, a measure of mitochondrial viability. In brief, cells were harvested from exponential phase cultures growing in DMEM supplemented with $10 \%$ FBS, counted, and plated in 96-well flat-bottomed microtiter plates $\left(1 \times 10^{4}\right.$ cells $\left./ \mathrm{ml}\right)$. After $72 \mathrm{~h}$ of continuous exposure to paclitaxel $\left(\right.$ Taxol $^{\circledR}$, BMS, Montreal, Canada), cells were incubated with MTT substrate $(20 \mathrm{mg} / \mathrm{ml})$ for $4 \mathrm{~h}$, the culture medium was removed, and DMSO was added. The optical density was measured spectrophotometrically at $550 \mathrm{~nm}$. Each experiment was repeated at least 3 times.

Western blotting. Equal amounts of protein from whole cell extracts were electrophoresed by denaturing $10 \%$ SDSPAGE. Proteins were transferred onto nitrocellulose membrane and stained with Ponceau S (Sigma) to confirm equal loading. Standard blocking and washing techniques were used, and the membranes were incubated with primary antiTACC3 antibody (Santa Cruz Biotechnology, Santa Cruz, CA), and anti-ß-actin (Sigma) in blocking buffer, followed by detection with anti-rabbit or anti-mouse IgG (Santa Cruz Biotechnology) conjugated to horseradish peroxidase. Bands were visualized using an ECL kit (Amersham Bioscience).

$R T-P C R$. Total RNA was isolated from cells using the RNeasy ${ }^{\circledR}$ Mini kit (Qiagen, Germany). Reverse transcription was carried out at $50^{\circ} \mathrm{C}$ for $30 \mathrm{~min}$, followed by $94^{\circ} \mathrm{C}$ for $2 \mathrm{~min}$ and a first round of PCR (30 cycles) of $95^{\circ} \mathrm{C}$ for $1 \mathrm{~min}, 56^{\circ} \mathrm{C}$ for $1 \mathrm{~min}$ and $68^{\circ} \mathrm{C}$ for $1 \mathrm{~min}$, with a final extension at $68^{\circ} \mathrm{C}$ for 7 min using TACC3 specific primers. The mRNA levels of glyceraldehyde 3-phosphate dehydrogenase (GAPDH) were used as an internal control to normalize for the amount of RNA.

Luciferase assay. A 109-bp fragment of the human TACC3 promoter was amplified from genomic DNA by PCR using primers containing $\mathrm{XhoI}$ and BamHI restriction sites, and cloned into the pG4M-poly II luciferase vector via XhoI and BamHI restriction enzymes. HeLa cells were transfected with
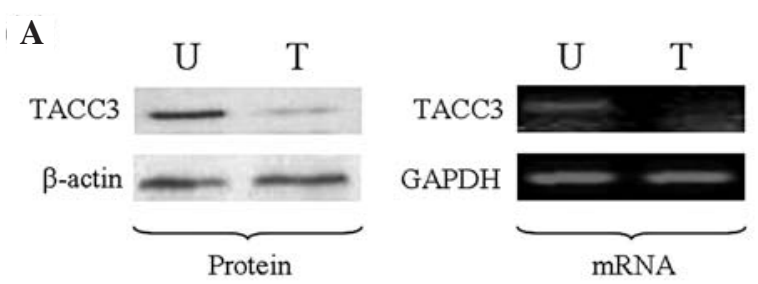

B
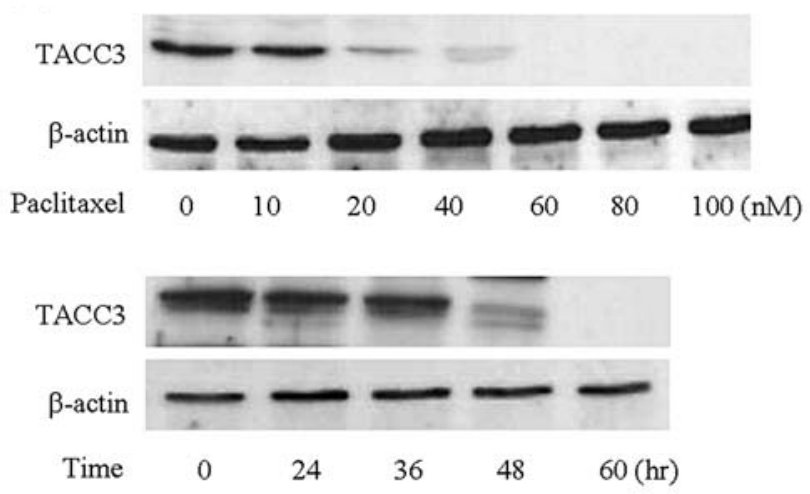

Figure 1. Effect of paclitaxel on TACC3 expression. (A) Western blotting and RT-PCR analysis of endogenous TACC3 protein and transcript levels in HeLa cells untreated (U) or treated with paclitaxel (T). B-actin and GAPDH were used as controls. (B) Expression of TACC3 protein in HeLa cells treated with various concentrations of paclitaxel. B-actin was used to normalize protein loading.

$2 \mu \mathrm{g}$ of either the pG4M-poly II luciferase vector driven by Gal4-fused to the TACC3 promoter sequence or the empty pG4M-poly II vector together with $0.5 \mu \mathrm{g}$ of a pCMV-driven vector encoding $\beta$-galactosidase. Three hours after transfection, the cells were treated with $20 \mathrm{nM}$ of paclitaxel for $24 \mathrm{~h}$. After removing the culture media and rinsing twice with $1 \mathrm{X}$ PBS, $500 \mu 1$ of $1 \mathrm{X}$ lysis buffer was added to the plates, which were then shaken at room temperature for $15 \mathrm{~min}$. The luciferase activity was determined using a luciferase assay system (Promega, Madison, WI), and the luciferase activity of each sample was normalized to $B$-galactosidase activity. Each experiment was repeated at least 3 times.

Short interference RNA transfection. TACC3, and scrambled siRNAs ('Stealth RNA') were obtained from Invitrogen (Carlsbad, CA). The siRNA sequences were as follows: TACC3, 5'-CCAAAUGGUGUCUCCAGGATT-3' (sense strand) and 5'-UCCUGGAGACACCAUUUGGTT-3' (antisense strand). A scrambled siRNA (control siRNA) was synthesized for use as the control. One day prior to transfection, cells were plated in the appropriate amount of growth medium without antibiotics to ensure $30-50 \%$ confluence at the time of transfection. After $24 \mathrm{~h}$, the cells were transfected with TACC 3 siRNA or control siRNA at 100 pmol in serum-free medium using Lipofectamine 2000 (Invitrogen). DMEM with $10 \%$ fetal bovine serum was added after $4 \mathrm{~h}$ at $37^{\circ} \mathrm{C}$, and samples were incubated for another $48 \mathrm{~h}$. After $48 \mathrm{~h}$, total $\mathrm{mRNA}$ and protein lysates were harvested from cells and analyzed by RT-PCR and Western blotting. 
A1

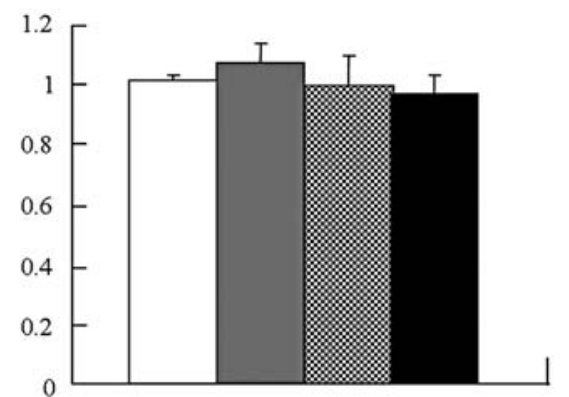

A2

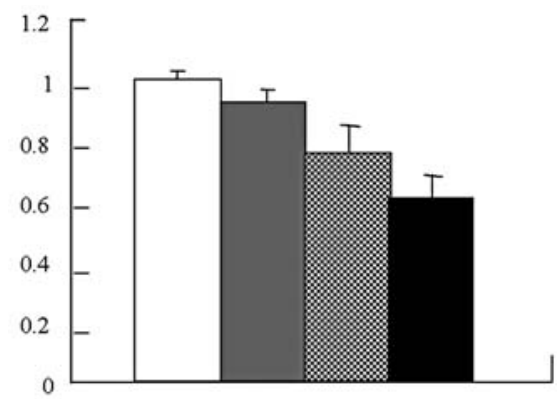

B
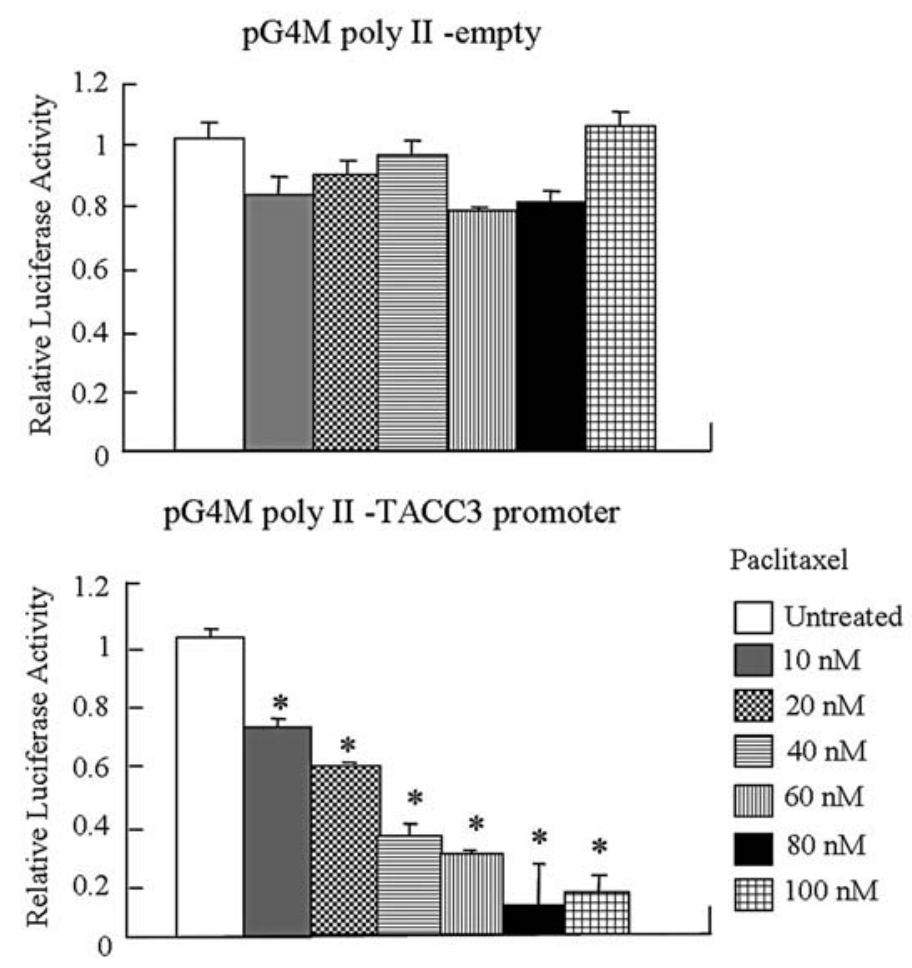

Figure 2. Paclitaxel decreased luciferase activity from construct containing TACC 3 promoter. The luciferase control plasmid or the construct driven by the TACC 3 promoter was transiently transfected into HeLa cells along with the B-galactosidase reporter plasmid as an internal control. (A) Transfected cells were treated with $20 \mathrm{nM}$ paclitaxel and assessed for luciferase activity after various periods of time, ranging from 0 to $24 \mathrm{~h}$. (B) Cells were transfected and treated with paclitaxel at various concentrations as indicated, and the luciferase activity was assessed after $48 \mathrm{~h}$. Activity was normalized to $\beta$-galactosidase activity to determine the relative luciferase activity. These experiments were performed 4 times. ${ }^{*} \mathrm{p}<0.05$.

FACS analysis. For cell cycle analysis, cells were treated with $20 \mathrm{nM}$ of paclitaxel for $24 \mathrm{~h}$. Cells were washed in $1 \mathrm{X}$ PBS and fixed for $1 \mathrm{~h}$ in $70 \%$ ethanol at $4^{\circ} \mathrm{C}$. After treatment with $50 \mu \mathrm{g} / \mathrm{ml} \mathrm{RNase} \mathrm{(Sigma)} \mathrm{for} 20 \mathrm{~min}$ at room temperature, cells were washed with PBS and incubated with $40 \mu \mathrm{g} / \mathrm{ml}$ propidium iodide (PI) (Sigma) for $30 \mathrm{~min}$. All samples were analyzed using a FACS System (FACSCalibur, Becton Dickinson, Mountain View, CA).

Analysis of chromatin condensation and segregation. Paclitaxel-treated cells were harvested, washed in 1X PBS, fixed with $4 \%$ paraformaldehyde, and stained for $5 \mathrm{~min}$ in $0.1 \mathrm{mg}$ of DAPI (Sigma) in methanol. Treated cells were analyzed via fluorescence microscopy to assess chromatin condensation and segregation.

Establishment of a stable TACC 3 cell line. The cDNA sequences of mTACC3 were deposited in the Genbank database (accession no. AF093542). mTACC3 cDNA was subcloned into the pcDNA3-HA vector downstream of the cytomegalovirus (CMV) promoter. To generate stable TACC3 transformants, HeLa cells were transfected with pcDNA3-HA-mTACC3 using Lipofectamine plus reagent (Invitrogen), and cells were cultured by selection in medium containing $2 \mathrm{mg} / \mathrm{ml}$ neomycin (G418, Gibco BRL). pcDNA3-HA empty vector was transfected in HeLa cells as a control.

Microarray analysis. cDNA microarray chips containing 14K mouse genes (known gene: 9,052) supplied by Digital Genomics (Seoul, Korea) were used. Each hybridization reaction was started with $15 \mu \mathrm{g}$ total RNA. Cy3/Cy5 fluorescent dye (Amersham Pharmacia, Piscataway, NJ) labeling and hybridization were carried out by Digital Genomics. Signals hybridized with Cy3- and Cy5-labeled probes were read at 532 and $635 \mathrm{~nm}$ by using ScanArray 3.0 (Packard). Image data were analyzed using GenePix Pro 4.0 (Axon Instruments, Burlingame, CA). 
A
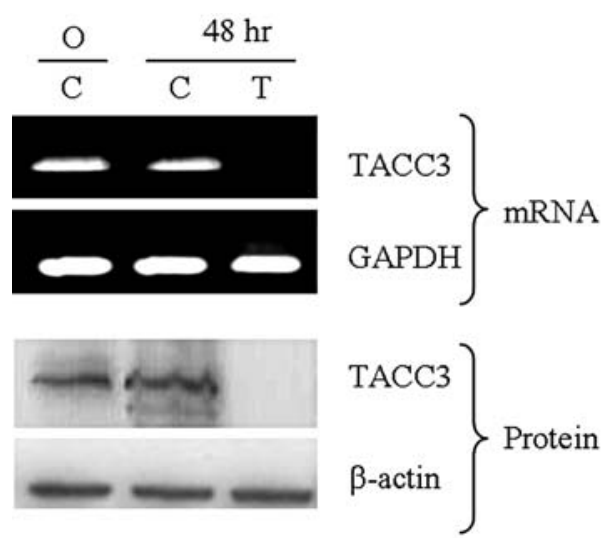

C

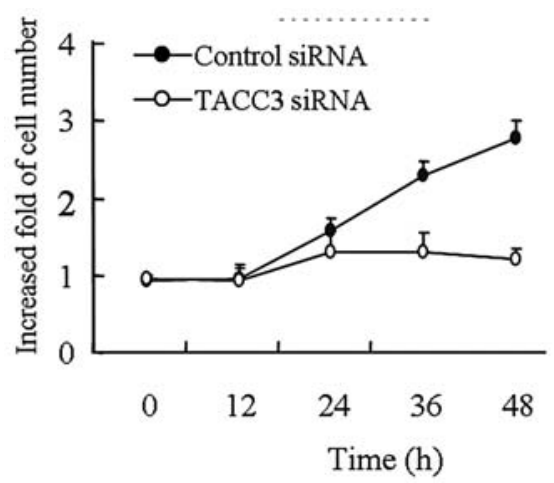

Statistical analysis. All observations were confirmed by at least three independent experiments. The Student's t-test was used to evaluate the statistical significance of mean values. Values of $p<0.05$ were considered to be significant.

\section{Results}

Paclitaxel down-regulated transcriptional activity of TACC3 promoter and TACC 3 expression in HeLa cells. The cell survival rate was significantly reduced by paclitaxel treat-

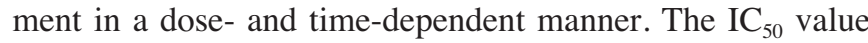
of paclitaxel was determined by interpolation from the curves, and found to be $20 \mathrm{nM}$ for HeLa cells.

To assess the effects of paclitaxel on TACC 3 protein and mRNA levels, cells were harvested after $48 \mathrm{~h}$ of treatment with paclitaxel, and their total lysates and mRNA were analyzed by Western blotting and RT-PCR. As shown in Fig. 1A, dramatic suppression of both TACC3 mRNA and protein expression was observed in response to paclitaxel. Furthermore, the partial to complete suppression of TACC3 protein levels occurred in a time- and dose-dependent manner (Fig. 1B). Based on our data that paclitaxel decreased TACC 3 mRNA levels, we next used a transient TACC 3 promoter luciferase reporter assay to evaluate whether paclitaxel could decrease TACC 3 promoter activity in HeLa cells. Upon exposure of HeLa cells transfected with the pG4M poly II luciferase vector driven by TACC3 promoter to $20 \mathrm{nM}$ paclitaxel, we observed a marked and time-dependent decrease in luciferase activity (Fig. 2A). We also found that paclitaxel treatment diminished TACC 3
B

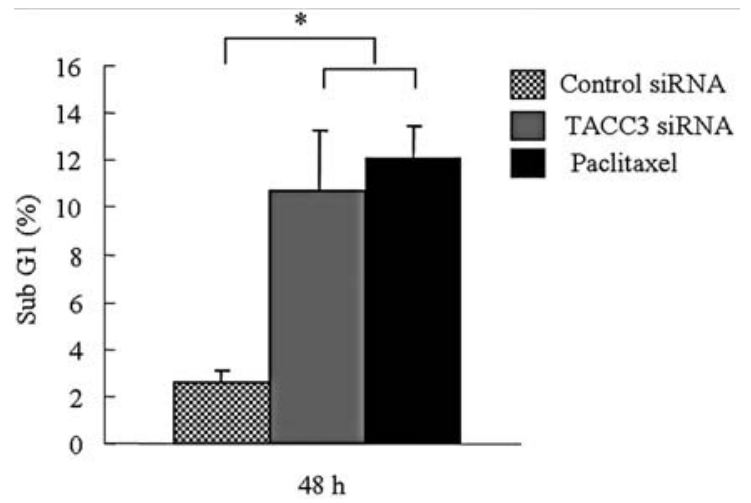

Figure 3. Effect of siRNA-mediated knockdown of TACC3 on the cell cycle and cell growth. (A) Transfection of TACC3 siRNA (100 pmol) in HeLa cells effectively knocked down TACC3 mRNA and protein after $48 \mathrm{~h}$ as confirmed by RT-PCR and Western blotting. A scrambled version of TACC3 siRNA (C) was used as a negative control. C, control; T, TACC3 siRNA. (B) Cells were transfected with 100 pmol of control or TACC3 siRNA or treated with $20 \mathrm{nM}$ paclitaxel for $48 \mathrm{~h}$ and processed for FACS analysis as described in Materials and methods. Cell cycle analysis was performed by flow cytometry, utilizing a commercially available software program. These experiments were performed in triplicate. (C) MTT assays. Cells were transfected with 100 pmol of TACC 3 or control siRNA and incubated for various lengths of time. The time-dependent, anti-proliferative effect of TACC3 siRNA on the growth of cervical carcinoma cells was measured by the MTT assay. These experiments were performed 4 times.

promoter activity in a dose-dependent manner (Fig. 2B). Together these results indicate that paclitaxel exerts inhibitory effects on TACC 3 gene transcription.

Cell cycle and cell growth effects in TACC3 siRNA treated HeLa cells. To address whether TACC 3 could be a suitable pharmacological target for paclitaxel cytotoxicity, we first employed the RNA interference (RNAi) system in cultured HeLa cells and confirmed a dramatic decrease in TACC3 mRNA transcript and protein levels (Fig. 3A). We analyzed the cell cycle distribution after transfection of TACC 3 siRNA in HeLa cells. As shown in Fig. 3B, we observed an increase in the $\mathrm{G} 2 / \mathrm{M}$ population with a concomitant decrease in the G0/G1 population after TACC3 siRNA treatment in HeLa cells. Moreover, after $48 \mathrm{~h}$, we observed an obvious and significant increase in the sub-G1 population. We also observed that the effect of knockdown of TACC 3 on the cell cycle was similar to that of paclitaxel. We investigated the effects of TACC3 siRNA on the growth of HeLa cells. HeLa cell proliferation was significantly suppressed by TACC 3 siRNA compared with control siRNA (Fig. 3C).

Together these results indicated that RNAi-mediated specific knockdown of TACC 3 induced abnormal accumulation of cells in the G2/M phase, strong inhibition of cell growth in vitro, and apoptosis.

Knockdown of TACC3 significantly enhances the cytotoxicity of paclitaxel. Based on the ability of RNAi-mediated knockdown of TACC 3 to arrest cells in G2/M phase, we speculated that it could synergistically enhance the cytotoxicity 


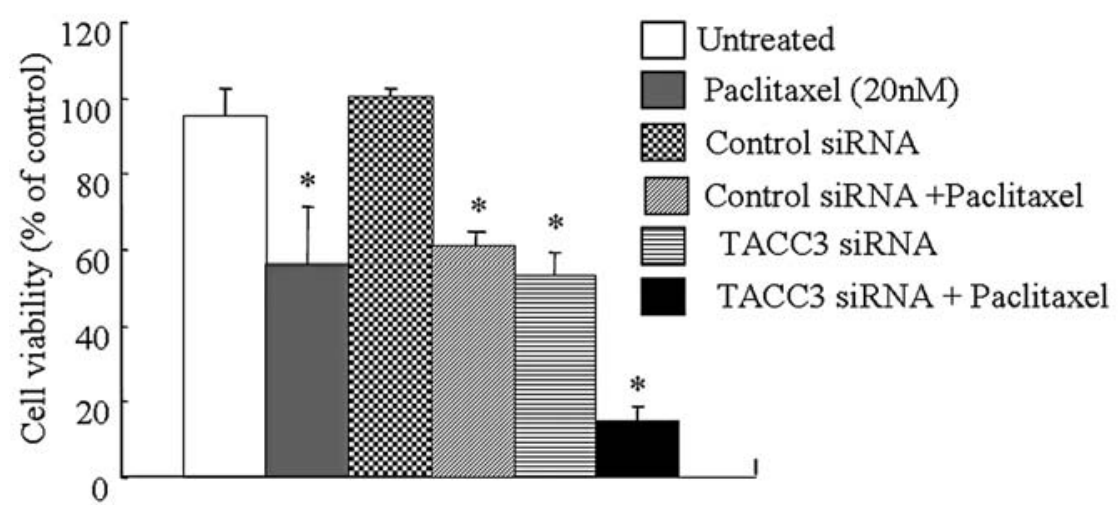

Figure 4. Synergistic effect of knockdown of TACC3 and paclitaxel treatment on cytotoxicity. Viable HeLa cells quantified by MTT assay after transfection with control or TACC3 siRNA, treatment with $20 \mathrm{nM}$ of paclitaxel, or a combination of the two. These experiments were performed 4 times. * $<<0.05$.

A

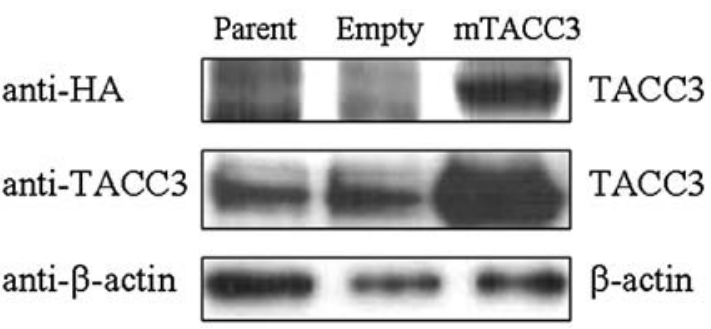

C

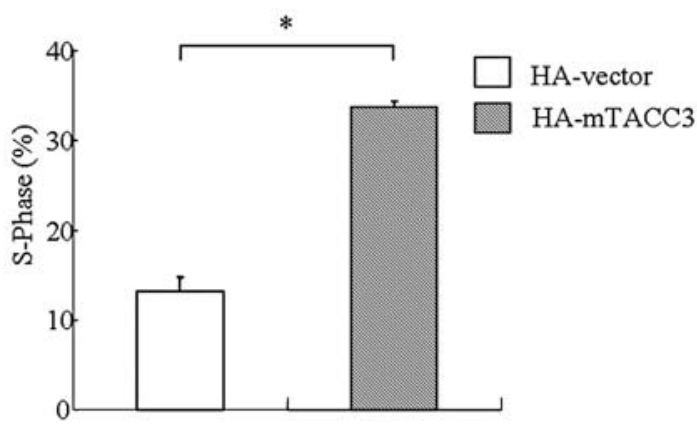

B

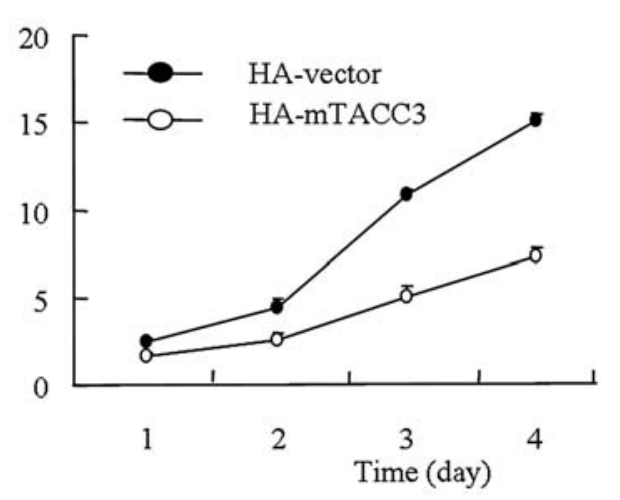

Figure 5. Establishment and characterization of the mTACC3overexpressing stable cell line. (A) Western blot analysis for HA, TACC3, and $B$-actin in untransfected HeLa cells (parent), HeLa cells overexpressing the empty HA vector (empty), and HA-mTACC3-overexpressing HeLa cells (mTACC3). (B) Cell growth analysis by MTT assay of HA-vector and HA-mTACC 3 overexpressing HeLa cells over 5 days. These experiments were performed 4 times. (C) FACS analysis of HA-vector and HAmTACC3 stable cell lines. Total amount of cells in S-phase was determined by flow cytometry. These experiments were performed 4 times. ${ }^{*} \mathrm{p}<0.05$.

affect cancer cell resistance to paclitaxel cytotoxicity in vitro. To address this question, we established a stable transfectant HeLa cell line expressing mouse TACC3 (mTACC3). The mTACC3-overexpressing HeLa cell line showed elevated expression of the exogenous TACC3 protein (Fig. 5A). mTACC3-overexpressing HeLa cells showed cell overgrowth (Fig. 5B) and S-phase delay (Fig. 5C) as compared with control cells. We next determined whether the overexpression of TACC 3 would affect cancer cell resistance against paclitaxel cytotoxicity in vitro. We analyzed the cell cycle distribution after paclitaxel treatment of mTACC3overexpressing HeLa cells. As shown in Fig. 6A, compared to the pronounced effect of paclitaxel on G2/M and sub-G1 accumulation in control cells, no change was observed in cell cycle distribution upon paclitaxel treatment of cells overexpressing mTACC3. Moreover, unlike the morphological

changes observed in control cells treated with paclitaxel,
Resistance of TACC3-overexpressing cells to paclitaxel. We

wondered whether the overexpression of TACC 3 would of paclitaxel. To assess this possibility, we investigated the synergistic effects of TACC 3 siRNA and paclitaxel in HeL com siRNA treatment. Altho ingle treatment with TACC 3 siRNA or paclitaxel induced to effect of paclitaxel by TACC3 siRNA indicate that RNAi-mediated specific knock-down of can synergistically enhance the chemosensitivity of cells to paclitaxel. 
A

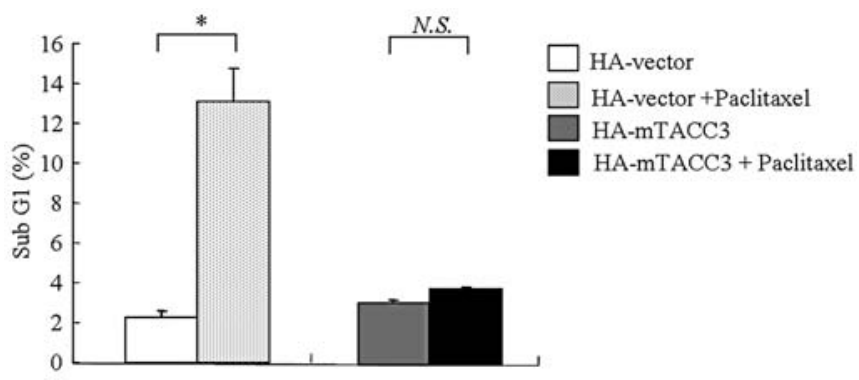

C
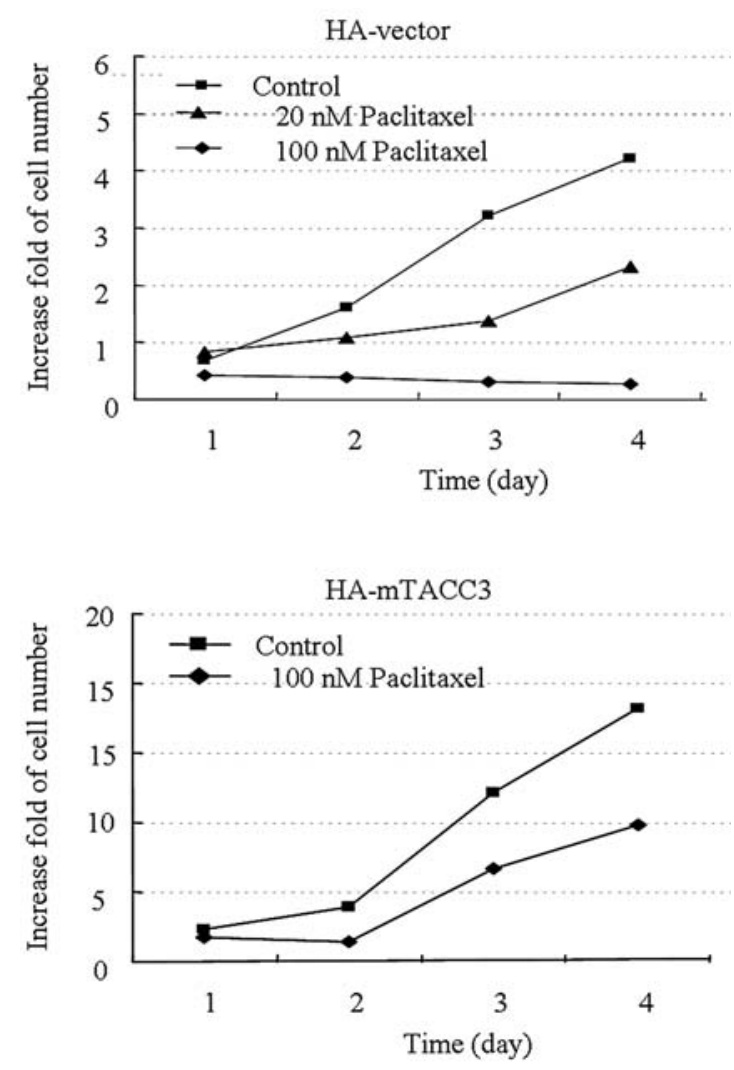

mTACC3-overexpressing HeLa cells did not show any increase of cells with apoptotic morphology (Fig. 6B). Cellular proliferation was evaluated by the MTT assay daily for 4 days, and treatment with $20 \mathrm{nM}$ paclitaxel had no effect on the proliferation of mTACC3-overexpressing HeLa cells. Even at paclitaxel concentrations over 3 times the $\mathrm{IC}_{50}$ value, only a slight decrease in cell growth was observed (Fig. 6C). These results indicate that stable expression of mTACC3 is strongly associated with resistance to paclitaxel treatment.

Gene expression changes by mTACC 3 overexpression in HeLa cells. Table I showed list of selected genes that were up-regulated by mTACC 3 overexpression. There is several up-regulated genes with previously reported in mechanisms of chemoresistance [Akt (14), Plk-1 (15), MAP kinase (16)], tumor progression and proliferation [Ppia (7), TMSB10 (17), Annexin A2 (18), rab31 (19), prostaglandin E2-EP2 (20),
B

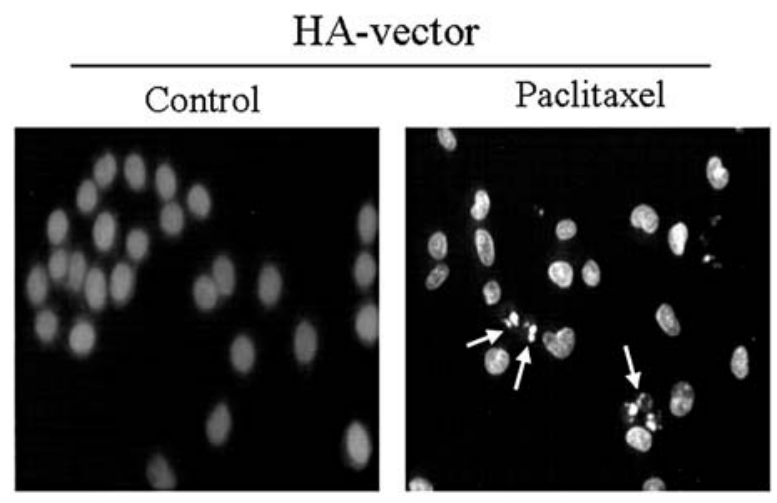

\section{HA-mTACC3}

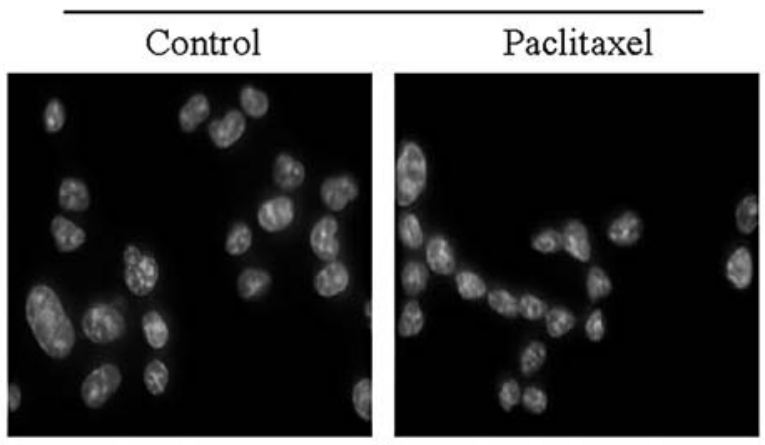

Figure 6. Resistance of the mTACC3-overexpressing HeLa cell line to paclitaxel. (A) HA-vector and HA-mTACC3 stable cells were treated with $20 \mathrm{nM}$ of paclitaxel for $48 \mathrm{~h}$ and evaluated for DNA content after propidium iodide staining by FACS analysis. These experiments were performed four times. ${ }^{*} \mathrm{p}<0.05$. N.S., not significantly different. (B) HA-vector and HAmTACC3 stable cell lines were treated with $20 \mathrm{nM}$ of paclitaxel and stained with DAPI. Arrows indicate cells undergoing apoptosis as detected by altered nuclear morphology. Stained nuclei were visualized under a fluorescence microscope (x200). (C) HA-vector and HA-mTACC3 stable HeLa cells were seeded overnight, exposed to 0,20 , or $100 \mathrm{nM}$ of paclitaxel for 4 days and MTT assays were performed. These experiments were performed 3 times.

UHRF1 (21)], and metastasis associated molecules [MMP9 $(22,23)$, PECAM-1 (24)].

Table II shows a list of selected genes that were downregulated by mTACC3 overexpression. This list includes genes that are implicated in chemosensitivity [caspase-3(25), E2F-4(26), IGF1R(27)], cell cycle regulation (ubiquitineactivating enzyme E1C, Gspt2, Itgb1, calcium/calmodulindependent protein kinase II $\gamma$, growth arrest and DNAdamage-inducible $45 \alpha$ ), and apoptosis (caspase 3, cell division cycle and apoptosis regulator 1 , traf4).

\section{Discussion}

Paclitaxel-induced cytotoxicity is associated directly with mitotic arrest (28) or following an aberrant mitotic exit $(28,29)$. However, the mechanisms downstream of the stabilization of microtubule dynamics leading to apoptosis remain unclear, and the mitotic spindle assembly check- 
Table I. Genes up-regulated by mTACC3 overexpression.

\begin{tabular}{|c|c|c|}
\hline Functional category & GenBank accession no. & Gene name \\
\hline Apoptosis & NM_009652 & Thymoma viral proto-oncogene 1 (Akt1) \\
\hline \multirow[t]{3}{*}{ Cell cycle } & AK076351 & Extra spindle poles-like 1 \\
\hline & NM_011121 & Polo-like kinase 1 (Drosophila) \\
\hline & ВC023116 & Cell growth regulator with EF hand domain 1 \\
\hline \multirow[t]{13}{*}{ Cellular physiology } & NM_011295 & Ribosomal protein S12 \\
\hline & NM_008907 & Peptidylprolyl isomerase A (Ppia) \\
\hline & NM_021278 & Thymosin, $\beta 4$, X chromosome \\
\hline & NM_172086 & Ribosomal protein L32 \\
\hline & NM_013798 & Actin, $\gamma$, cytoplasmic 1 \\
\hline & NM_008503 & Phosphodiesterase 6A, cGMP-specific, rod, $\alpha$ (Pde6a) \\
\hline & NM_016682 & Ubiquitin-like 1 (sentrin) activating enzyme E1B (Uble1b) \\
\hline & NM_010448 & Heterogeneous nuclear ribonucleoprotein A/B (Hnrpab) \\
\hline & NM_025284 & Thymosin, $\beta 10$ (Tmsb10) \\
\hline & NM_010880 & Nucleolin \\
\hline & NM_007585 & Annexin A2 \\
\hline & NM_019472 & Myosin X \\
\hline & NM_013599 & Matrix metallopeptidase 9 (Mmp9) \\
\hline Immune response & NM_133212 & Toll-like receptor 8 (Tlr8) \\
\hline Response to stress & NM_008302 & Heat shock protein $1, ß$ (Hspcb) \\
\hline \multirow[t]{6}{*}{ Signal transduction } & NM_009062 & Regulator of G-protein signaling 4 \\
\hline & NM_146592 & Olfactory receptor 1086 (Olfr1086) \\
\hline & AK043482 & MAP Kinase Kinase \\
\hline & NM_008816 & Platelet/endothelial cell adhesion molecule 1 , transcript variant 2 \\
\hline & NM_008964 & Prostaglandin E receptor 2 (subtype EP2) \\
\hline & NM_133685 & RAB31, member RAS oncogene family (Rab31) \\
\hline \multirow[t]{4}{*}{ Transcription } & BU611745 & RIKEN cDNA A630018P17 gene (A630018P17Rik) \\
\hline & NM_010710 & LIM-homeodomain protein MLHX2 (Lhx2) \\
\hline & NM_010931 & Ubiquitin-like, containing PHD and RING finger domains, 1 \\
\hline & AF448482 & Homeo box C12 (Hoxc12) \\
\hline
\end{tabular}

point has been proposed to regulate paclitaxel-initiated apoptosis (30). TACC3, one of the important structural components of the centrosome/spindle apparatus (31). stabilizes centrosomal microtubules and is required to recruit ch-TOG/XMAP215/Msps to the centrosome in an Aurora-A regulated manner $(32,33)$. This complex is critical to maintain centrosome integrity, centrosome-dependent assembly of microtubules and spindle stability $(34,35)$.

Our results showed that paclitaxel diminished TACC3 transcription in a time- and dose-dependent manner. TACC3 knockdown only was a similar change to that of paclitaxel treatment in HeLa cells. Both paclitaxel treatment and RNAimediated knockdown of TACC3 induced significant G2/M phase arrest, strong suppression of growth, and eventual cell apoptosis. In contrast to TACC3-deficient cells, paclitaxel treatment failed to induce $\mathrm{G} 2 / \mathrm{M}$ phase arrest, cell growth inhibition, or apoptosis in mTACC3-overexpressing HeLa cells. Interestingly, minimal cytotoxicity was observed at a concentration of paclitaxel that was $>3$ times the $\mathrm{IC}_{50}$. These results indicate that stable expression of mTACC 3 is associated with resistance to paclitaxel treatment.

Consistent with the results from Schneider et al (12) we found a synergistic enhancement of paclitaxel cytotoxicity after RNAi-mediated knockdown of TACC3 in HeLa cells. However, they discussed that TACC3-depleted cells had different effects on cell cycle progression depending on the presence or absence of functional p53 (12). Paclitaxel induced p53- and p21-dependent arrest in postmitotic G1 or G2 arrest in cell type-dependent fashion $(12,36)$. However, most cancer cells including HeLa cells had the mutated or inactivated p53 gene (37). Unlike postmitotic arrest, mitotic arrest and apoptosis are p53-independent $(28,38,39)$. In these reports, both paclitaxel treatment and knockdown of TACC3 induced significant G2/M phase arrest and apoptosis. In our previous study, we observed dual apoptotic pathways by paclitaxel treatment in HeLa cells, through the membrane 
Table II. Genes down-regulated by mTACC3 overexpression.

\begin{tabular}{|c|c|c|}
\hline Functional category & GenBank accession no. & Gene name \\
\hline \multirow[t]{5}{*}{ Cell cycle } & NM_011666 & Ubiquitin-activating enzyme E1C \\
\hline & NM_008179 & G1 to $\mathrm{S}$ phase transition 2 (Gspt2) \\
\hline & AK088016 & Integrin $\beta 1$ (fibronectin receptor $\beta$ ) (Itgb1) \\
\hline & AK078311 & Calcium/calmodulin-dependent protein kinase II $\gamma$ \\
\hline & NM_007836 & Growth arrest and DNA-damage-inducible $45 \alpha$ \\
\hline \multirow[t]{3}{*}{ Apoptosis } & NM_009810 & Caspase 3 \\
\hline & AF465615 & Cell division cycle and apoptosis regulator 1 \\
\hline & NM_009423 & TNF receptor associated factor $4(\operatorname{traf} 4)$ \\
\hline \multirow[t]{6}{*}{ Transcription } & NM_139117 & Cold shock domain protein A (Csda) \\
\hline & NM_148952 & E2F transcription factor 4 \\
\hline & AK088142 & Minichromosome maintenance deficient 3) \\
\hline & NM_008229 & Histone deacetylase 2 (Hdac2) \\
\hline & AK088142 & Minichromosome maintenance deficient 3 \\
\hline & NM_008186 & General transcription factor II H, polypeptide 1 (Gtf2h1) \\
\hline \multirow[t]{5}{*}{ Cellular physiology } & NM_172394 & Nucleoporin 88 \\
\hline & NM_007830 & Diazepam binding inhibitor \\
\hline & NM_025859 & ADP-ribosylation factor-like 1 (Arl1) \\
\hline & NM_016754 & Myosin light chain, phosphorylatable, fast skeletal muscle \\
\hline & NM_009128 & Stearoyl-Coenzyme A desaturase 2 (Scd2) \\
\hline \multirow[t]{12}{*}{ Response to stress } & NM_009825 & Serine (or cysteine) peptidase inhibitor, clade $\mathrm{H}$, member 1 \\
\hline & NM_133804 & Heat shock $70 \mathrm{kDa}$ protein 5 binding protein 1 (Hspa5bp1) \\
\hline & NM_008303 & Heat shock protein 1 (chaperonin 10) \\
\hline & NM_028450 & GULP, engulfment adaptor PTB domain containing 1 \\
\hline & NM_011363 & PSM/SH2-B delta (Sh2bpsm1) \\
\hline & NM_029576 & RAB1B, member RAS oncogene family (Rab1b) \\
\hline & ВC033382 & RAS related protein $1 \mathrm{~b}$ \\
\hline & NM_016719 & Growth factor receptor bound protein 14 \\
\hline & AK087668 & Insulin-like growth factor I receptor (Igf1r) \\
\hline & NM_008543 & MAD homolog 7 (Drosophila) (Smad7) \\
\hline & NM_007982 & PTK2 protein tyrosine kinase 2 \\
\hline & AK088016 & Integrin $\beta 1$ (fibronectin receptor $ß$ ) (Itgb1) \\
\hline
\end{tabular}

death receptor (TRAIL)-mediated apoptotic pathway and cytochrome-c-dependent (bcl-2-mediated) apoptotic pathway (2). Recent studies demonstrated that Akt activation plays a significant role in protection of TRAIL-induced apoptosis and Akt dephosphorypation induced by paclitaxel correlated with TRAIL sensitization (40). We studied the associated gene in mTACC overexpressed cells using microarray. From these results, numerous genes have been identified as being associated with tumor progression and chemoresistance in mTACC3 overexpressed HeLa cells. Akt was also up-regulated having shown chemoresistance phenotype through its antiapoptotic activity (14). A recent study (15) showed Plk-1 association with gencitabine chemosensitivity. The MAP kinase showed up-regulation in these studies, consistent with previous reports suggesting a relationship between MAPK gene expression and paclitaxel cytotoxicity (16). On the other hand, some genes involved in chemosensitivity [caspase-3 (25), E2F-4 (26), IGF1R (27)] were observed to be down-regulated in mTACC3 overexpressed HeLa cells.

In summary, TACC3 is thought to be the critical molecule in mediating the anticancer mechanisms of paclitaxel in p53 inactivated cells by inducing G2/M arrest and apoptosis. Our data suggest that the overexpression of TACC 3 may be associated with the mechanisms of chemoresistance, tumor progression, cell proliferation and metastasis. Although further in vivo validations for the identified genes are required because the materials used in the study were induced cells in vitro, this important information may lead to the discovery of new paclitaxel resistance targets. Further detailed investigation is needed to understand the mutual relationship and molecular function of TACC 3 for paclitaxel treatment in cervical carcinoma cells. 


\section{Acknowledgements}

This study was supported by the Korea Research Foundation Grant (KRF-2005-041-E00229).

\section{References}

1. Jordan MA and Wilson L: Microtubules as a target for anticancer drugs. Nat Rev Cancer 4: 253-265, 2004.

2. Lee KH, Yim EK, Kim CJ, Namkoong SE, Um SJ and Park JS: Proteomic analysis of anti-cancer effects by paclitaxel treatment in cervical cancer cells. Gynecol Oncol 98: 45-53, 2005.

3. Ferlini C, Raspaglio G, Mozzetti S, et al: The seco-taxane IDN5390 is able to target class III beta-tubulin and to overcome paclitaxel resistance. Cancer Res 65: 2397-2405, 2005.

4. Berrieman HK, Lind MJ and Cawkwell L: Do beta-tubulin mutations have a role in resistance to chemotherapy? Lancet Oncol 5: 158-164, 2004.

5. van Ark-Otte J, Samelis G, Rubio G, Lopez Saez JB, Pinedo HM and Giaccone G: Effects of tubulin-inhibiting agents in human lung and breast cancer cell lines with different multidrug resistance phenotypes. Oncol Rep 5: 249-255, 1998.

6 Goncalves A, Braguer D, Kamath K, et al: Resistance to Taxol in lung cancer cells associated with increased microtubule dynamics. Proc Natl Acad Sci USA 98: 11737-11742, 2001.

7. L'Esperance S, Popa I, Bachvarova M, et al: Gene expression profiling of paired ovarian tumors obtained prior to and following adjuvant chemotherapy: molecular signatures of chemoresistant tumors. Int J Oncol 29: 5-24, 2006.

8. Still IH, Hamilton M, Vince P, Wolfman A and Cowell JK: Cloning of TACC1, an embryonically expressed, potentially transforming coiled coil containing gene, from the $8 \mathrm{p} 11$ breast cancer amplicon. Oncogene 18: 4032-4038, 1999.

9. Still IH, Vince P and Cowell JK: The third member of the transforming acidic coiled coil-containing gene family, TACC3, maps in $4 \mathrm{p} 16$, close to translocation breakpoints in multiple myeloma, and is upregulated in various cancer cell lines. Genomics 58: 165-170, 1999.

10. McKeveney PJ, Hodges VM, Mullan RN, et al: Characterization and localization of expression of an erythropoietininduced gene, ERIC-1/TACC3, identified in erythroid precursor cells. Br J Haematol 112: 1016-1024, 2001.

11. Piekorz RP, Hoffmeyer A, Duntsch CD, et al: The centrosomal protein TACC3 is essential for hematopoietic stem cell function and genetically interfaces with p53-regulated apoptosis. EMBO J 21: 653-664, 2002

12. Schneider L, Essmann F, Kletke A, et al: TACC3 depletion sensitizes to paclitaxel-induced cell death and overrides p21WAF-mediated cell cycle arrest. Oncogene 27: 116-125, 2008.

13. Debernardis D, Sire EG, De Feudis P, et al: p53 status does not affect sensitivity of human ovarian cancer cell lines to paclitaxel. Cancer Res 57: 870-874, 1997.

14. Gagnon V, Van Themsche C, Turner S, Leblanc V and Asselin E. Akt and XIAP regulate the sensitivity of human uterine cancer cells to cisplatin, doxorubicin and taxol. Apoptosis 13: 259-271, 2008.

15. Yu C, Zhang X, Sun G, et al: RNA Interference-mediated silencing of the polo-like kinase 1 gene enhances chemosensitivity to gemcitabine in pancreatic adenocarcinoma cells. J Cell Mol Med (In press).

16. Quan H, Xu Y and Lou L: p38 MAPK, but not ERK1/2, is critically involved in the cytotoxicity of the novel vascular disrupting agent combretastatin A4. Int J Cancer 122: 1730-1737, 2008 .

17. Alldinger I, Dittert D, Peiper M, et al: Gene expression analysis of pancreatic cell lines reveals genes overexpressed in pancreatic cancer. Pancreatology 5: 370-379, 2005.

18. Yu GR, Kim SH, Park SH, et al: Identification of molecular markers for the oncogenic differentiation of hepatocellular carcinoma. Exp Mol Med 39: 641-652, 2007.

19. Kotzsch M, Sieuwerts AM, Grosser M, et al: Urokinase receptor splice variant uPAR-del4/5-associated gene expression in breast cancer: identification of rab31 as an independent prognostic factor. Breast Cancer Res Treat 111: 229-240, 2008.

20. Spinella F, Rosano L, Di Castro V, Natali PG and Bagnato A: Endothelin-1-induced prostaglandin E2-EP2, EP4 signaling regulates vascular endothelial growth factor production and ovarian carcinoma cell invasion. J Biol Chem 279: 46700-46705, 2004.
21. Jenkins Y, Markovtsov V, Lang W, et al: Critical role of the ubiquitin ligase activity of UHRF1, a nuclear RING finger protein, in tumor cell growth. Mol Biol Cell 16: 5621-5629, 2005.

22. Heissig B, Hattori K, Friedrich M, Rafii S and Werb Z: Angiogenesis: vascular remodeling of the extracellular matrix involves metalloproteinases. Curr Opin Hematol 10: 136-141, 2003.

23. Ahn GO and Brown JM: Matrix metalloproteinase- 9 is required for tumor vasculogenesis but not for angiogenesis: role of bone marrow-derived myelomonocytic cells. Cancer Cell 13: 193-205, 2008.

24. Lutzky VP, Carnevale RP, Alvarez MJ, et al: Plateletendothelial cell adhesion molecule-1 (CD31) recycles and induces cell growth inhibition on human tumor cell lines. J Cell Biochem 98: 1334-1350, 2006.

25. Friedrich K, Wieder T, Von Haefen C, et al: Overexpression of caspase-3 restores sensitivity for drug-induced apoptosis in breast cancer cell lines with acquired drug resistance. Oncogene 20: 2749-2760, 2001

26. Nathan SS, DiResta GR, Casas-Ganem JE, et al: Elevated physiologic tumor pressure promotes proliferation and chemosensitivity in human osteosarcoma. Clin Cancer Res 11: 2389-2397, 2005.

27. Hellawell GO, Ferguson DJ, Brewster SF and Macaulay VM: Chemosensitization of human prostate cancer using antisense agents targeting the type 1 insulin-like growth factor receptor. BJU Int 91: 271-277, 2003.

28. Woods CM, Zhu J, McQueney PA, Bollag D and Lazarides E: Taxol-induced mitotic block triggers rapid onset of a p53independent apoptotic pathway. Mol Med 1: 506-526, 1995.

29. Jordan MA, Wendell K, Gardiner S, Derry WB, Copp H and Wilson L: Mitotic block induced in HeLa cells by low concentrations of paclitaxel (Taxol) results in abnormal mitotic exit and apoptotic cell death. Cancer Res 56: 816-825, 1996.

30. Wang TH, Wang HS and Soong YK: Paclitaxel-induced cell death: where the cell cycle and apoptosis come together. Cancer 88: 2619-2628, 2000.

31. Gergely F, Karlsson C, Still I, Cowell J, Kilmartin J and Raff JW: The TACC domain identifies a family of centrosomal proteins that can interact with microtubules. Proc Natl Acad Sci USA 97: $14352-14357,2000$.

32. Kinoshita K, Noetzel TL, Pelletier L, et al: Aurora A phosphorylation of TACC3/maskin is required for centrosomedependent microtubule assembly in mitosis. J Cell Biol 170: 1047-1055, 2005.

33. Fukasawa K: Centrosome amplification, chromosome instability and cancer development. Cancer Lett 230: 6-19, 2005.

34. Gergely F, Draviam VM and Raff JW: The ch-TOG/XMAP215 protein is essential for spindle pole organization in human somatic cells. Genes Dev 17: 336-341, 2003.

35. Schneider L, Essmann F, Kletke A, et al: The transforming acidic coiled coil 3 protein is essential for spindle-dependent chromosome alignment and mitotic survival. J Biol Chem 282: 29273-29283, 2007.

36. Giannakakou P, Robey R, Fojo T and Blagosklonny MV: Low concentrations of paclitaxel induce cell type-dependent p53, p21 and G1/G2 arrest instead of mitotic arrest: molecular determinants of paclitaxel-induced cytotoxicity. Oncogene 20: 3806-3813, 2001.

37. Greenblatt MS, Bennett WP, Hollstein M and Harris CC: Mutations in the p53 tumor suppressor gene: clues to cancer etiology and molecular pathogenesis. Cancer Res 54: 4855-4878, 1994.

38. Fan S, Cherney B, Reinhold W, Rucker K and O'Connor PM: Disruption of p53 function in immortalized human cells does not affect survival or apoptosis after taxol or vincristine treatment. Clin Cancer Res 4: 1047-1054, 1998.

39. Bacus SS, Gudkov AV, Lowe M, et al: Taxol-induced apoptosis depends on MAP kinase pathways (ERK and p38) and is independent of p53. Oncogene 20: 147-155, 2001.

40. Asakuma J, Sumitomo M, Asano T, Asano T and Hayakawa M: Selective Akt inactivation and tumor necrosis factor-related apoptosis-inducing ligand sensitization of renal cancer cells by low concentrations of paclitaxel. Cancer Res 63: 1365-1370, 2003. 